\title{
Successful Treatment of Mycoplasma hominis Meningitis, Diagnosed Using Real-Time Polymerase Chain Reaction, with Ciprofloxacin in a Neonate
}

\author{
Iktae Gwon, $\mathrm{MD}^{1}$, Woo Sun Song, $\mathrm{MD}^{1}$, Yong-Hak Sohn, $\mathrm{MD}, \mathrm{PhD}^{2}$, and Seung Yeon Kim, $\mathrm{MD}$, $\mathrm{PhD}^{1,3}$ \\ ${ }^{1}$ Department of Pediatrics, Daejeon Eulji Medical Center, Daejeon, Korea \\ ${ }^{2}$ Department of Laboratory Medicine, Seegene Medical Foundation, Seoul, Korea \\ ${ }^{3}$ Department of Pediatrics, Eulji University School of Medicine, Daejeon, Korea
}

\section{ABSTRACT}

Mycoplasma hominis can cause life-threatening central nervous system infections in neonates following intrauterine infection or during delivery. In newborns, the diagnosis and treatment of $M$. hominis meningitis are challenging, because cultures are often negative and the bacterium is not susceptible to empirical antibiotics. Herein, we describe a case of neonatal M. hominis meningitis diagnosed using real-time polymerase chain reaction (RT-PCR) and treated with ciprofloxacin. The patient was a 3-day-old female hospitalized for a fever and lethargy. Her blood laboratory findings were non-specific; cerebrospinal fluid (CSF) examination showed a white blood cell count of $580 / \mu \mathrm{L}$ and indicated meningitis. Her symptoms could not be controlled with empirical antibiotics. Urine culture on a special medium revealed ciprofloxacinsusceptible M. hominis. Furthermore, the RT-PCR performed with the CSF sample revealed M. hominis. Therefore, the patient was administered ciprofloxacin; after 2 days, the fever subsided. The patient was discharged on day 30 without complications.

Key Words: Mycoplasma hominis; Meningitis; Infant, newborn; Real-time polymerase chain reaction; Ciprofloxacin

\section{INTRODUCTION}

Mycoplasma hominis is generally associated with localized genitourinary tract infections including pelvic inflammatory diseases, pyelonephritis, and chorioamnionitis ${ }^{1}$. Neonates can be exposed to the microbe from a colonized birth canal, and they subsequently develop severe diseases such as respiratory tract infections, sepsis, and central nervous system infections ${ }^{2}$. The diagnosis and treatment of $M$. hominis meningitis in newborns can be challenging because the cultures are often negative and the microbe is not susceptible to empirical antibiotics. Additionally, there are several limitations associated with antibiotic
Received: 6 May 2020

Revised: 24 June 2020

Accepted: 25 June 2020

Correspondence to: Seung Yeon Kim, $\mathrm{MD}, \mathrm{PhD}$

Department of Pediatrics, Daejeon Eulji Medical Center, Eulji University School of Medicine, 95 Dunsanseo-ro, Seo-gu, Daejeon 35233, Korea Tel: +82-42-611-3391-2 Fax: +82-42-259-1111 E-mail: dunggiduk5@gmail.com

Copyright(c)

By Korean Society of Neonatology.

All right reserved.

This is an Open-Access article distributed under the terms of the Creative Commons At tribution Non-Commercial License (http:// creativecommons.org/licenses/by-nc/4.0), which permits unrestricted non-commercial use, distribution, and reproduction in any medium, provided the original work is pro perly cited. 
treatment of $M$. hominis meningitis in newborns, and the op timal treatment dose and duration have not been established. Herein, we present a case of successful treatment of M. hominis meningitis, diagnosed using real-time polymerase chain reaction (RT-PCR), with ciprofloxacin in a full-term infant.

\section{CASE REPORT}

A 3-day-old female child was hospitalized because of a fever and lethargy. She was born to a 29-year-old primigravida woman by uneventful vaginal delivery at 39 weeks of gestation after an uncomplicated pregnancy. Her birth weight was 3,730 g. On ad mission, she weighed 3,810 $\mathrm{g}$ and her body temperature was 38.7 ${ }^{\circ} \mathrm{C}$. Her physical and neurological examinations were normal except for a fever and lethargy. Meningitis was diagnosed based on her laboratory findings, especially cerebrospinal fluid (CSF) examination, which revealed a white blood cell count of $580 / \mathrm{mm}^{3}$ (Figure 1); therefore, ampicillin and cefotaxime were started. After 3 days, we repeated the laboratory examination and performed lumbar puncture because her fever persisted. The results indicated deterioration (Figure 1); therefore, the treatment was switched to vancomycin, meropenem, and acyclovir. The initial blood, CSF, and urine cultures were negative. Furthermore, the PCR per- formed with the CSF sample was negative for bacteria, herpes simplex virus, and enteroviruses. On day 6, urine culture (on a special culture medium) revealed $M$. hominis, which is susceptible to ciprofloxacin, doxycycline, josamycin, pristinamycin, and te tracycline; shows intermediate resistance/sensitivity to azithromycin, and is resistant to erythromycin and clarithromycin (Table 1). Among the antibiotics that have been shown to be effective against $M$. hominis, ciprofloxacin is the only drug that could be administered intravenously in our hospital. RT-PCR performed with the CSF sample on day 7 confirmed M. hominis; thus, the

Table 1. The Susceptibility of Antibiotics in Mycoplasma ho minis Culture: Growth (<10,000 CFU/Specimen)

\begin{tabular}{lc}
\hline Antibiotic & Susceptibility \\
\hline Azithromycin & $\mathrm{I}$ \\
Ciprofloxacin & $\mathrm{S}$ \\
Clarithromycin & $\mathrm{R}$ \\
Doxycycline & $\mathrm{S}$ \\
Erythromycin & $\mathrm{R}$ \\
Josamycin & $\mathrm{S}$ \\
Ofloxacin & $\mathrm{S}$ \\
Pristinamycin & $\mathrm{S}$ \\
Tetracycline & $\mathrm{S}$ \\
\hline
\end{tabular}

Abbreviations: CFU, colony forming unit; I, intermidate; S, susceptible; $\mathrm{R}$, resistant.

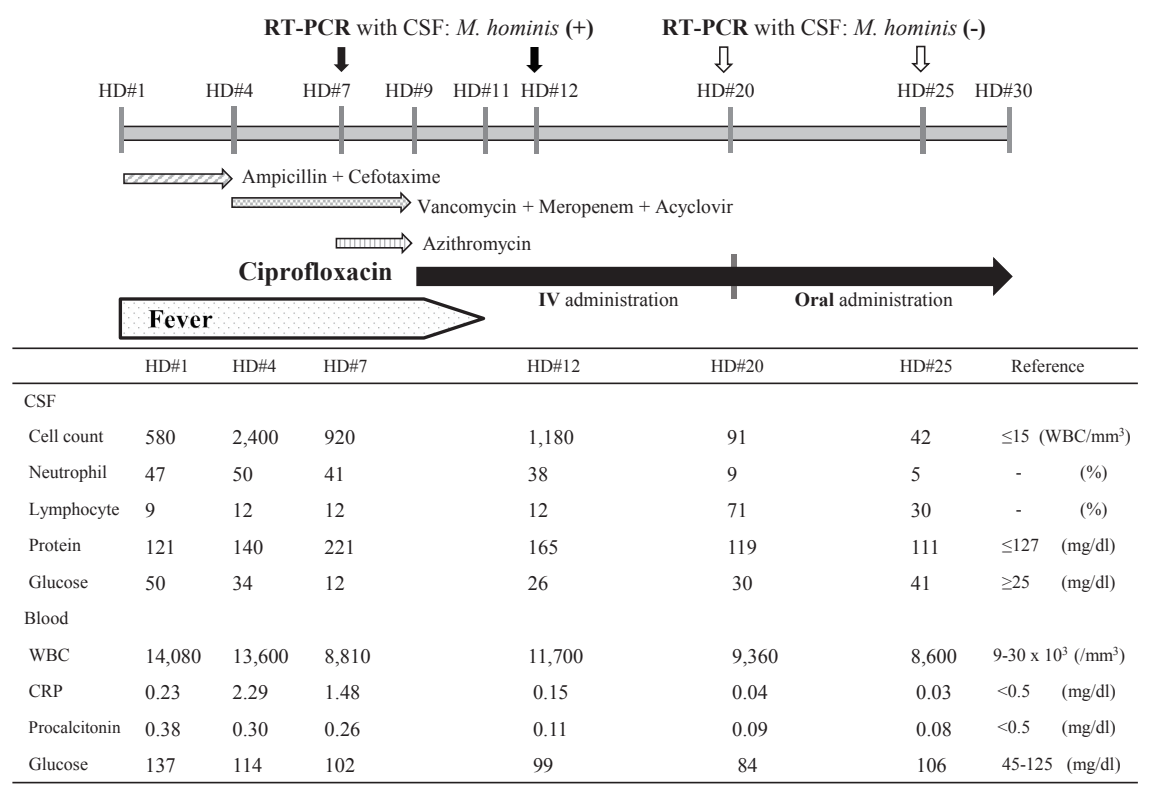

Figure 1. Disease schedule: fever, laboratory findings, real-time polymerase chain reaction diagnosis (RT-PCR), and antibiotics for treatment. Abbreviations: CSF, cerebrospinal fluid; M. hominis, Mycoplasma hominis; HD, hospital day; IV, intravenous; WBC, white blood cell; CRP, C-reactive protein. 
patient was diagnosed with $M$. hominis meningitis. On day 7, we added azithromycin, with intermediate efficacy against $M$. hominis, considering the adverse effects of ciprofloxacin. However, because the fever persisted even after 48 hours, on day 9, the antibiotics were switched to ciprofloxacin $11 \mathrm{mg} / \mathrm{kg} /$ dose every 12 hours. After 2 days, the fever subsided. On day 20, the follow-up RT-PCR was negative for $M$. hominis. After 11 days of intravenous administration, ciprofloxacin was administered orally for 10 days (Figure 1). The patient did not develop seizures and there were no abnormal findings in brain magnetic resonance imaging. $M$. hominis was not observed in the vaginal discharge of the mother. We speculated that this was because she received antibiotics during the postpartum period. However, because the baby was outborn, we could not exactly determine the kind of antibiotic that was administered to the mother. The patient was discharged on day 30 without complications. The patient showed normal growth and development at the 1-year follow-up.

\section{DISCUSSION}

Mycoplasma species are small pleomorphic bacteria of diameter 0.3 to $0.8 \mu \mathrm{m}$. They have a cell membrane with a high sterol content, but lack a cell wall. At least 15 Mycoplasma species have been isolated from humans. Among them, only three ( $M$. pneumoniae, M. hominis, and Ureaplasma urealyticum) are wellestablished human pathogens ${ }^{3)}$.

Mycoplasma and Ureaplasma species grow very slowly; hence, specific blood agar cultures are needed to obtain timely results. Isolation by culture is the gold standard for M. hominis detection; however, delayed diagnosis and ineffective antibiotic therapy due to slow or failed cultures can lead to high morbidity and mortality of individuals with $M$. hominis meningitis. Therefore, PCR is used for the early detection of M. hominis in clinical settings ${ }^{4,5}$. Compared with traditional PCR, RT-PCR has several advantages such as high speed, sensitivity, and specificity, and no post-PCR contamination $^{6}$. In our case, we could confirm the results by RTPCR in just 24 hours.

Mycoplasma species are not susceptible to antibiotics that inhibit cell wall synthesis, such as $\beta$-lactams, because they do not have a cell wall. Therefore, penicillins and cephalosporins used as an empirical therapy are ineffective. Besides, $M$. hominis is resistant to macrolides. In vitro tests have demonstrated the suscep tibility of $M$. hominis to chloramphenicol, tetracyclines, linco- samides, and fluoroquinolones ${ }^{7)}$. Chloramphenicol, tetracycline, and doxycycline have been used to treat $M$. hominis meningitis, although their safety in newborns has not been clearly establish. $\mathrm{ed}^{8,9)}$. Fluoroquinolones are effective against Mycoplasma sp ecies; however, their use in infants and children is limited due to concerns of cartilage damage ${ }^{7}$. Although they may cause adverse effects, quinolone-based antibiotics have been used to treat $M$. hominis meningitis. Among the fluoroquinolones, moxifloxacin and ciprofloxacin have been used to treat $M$. hominis meningitis in infants ${ }^{8,9}$. $M$. hominis has been shown to be more susceptible to fourth-generation fluoroquinolones than to second or third generation fluoroquinolones. For this reason, moxifloxacin, a fourthgeneration fluoroquinolone, is eligible for wider use against $M$. hominis $^{8,9)}$. The therapeutic and safety range doses of moxifloxacin for neonates are not clear, but we can obtain relevant information from several case reports. According to previous reports, for in fants, 5 to $13 \mathrm{mg} / \mathrm{kg}$ moxifloxacin per day is effective against $M$. hominis and is well tolerated ${ }^{7-9)}$. The optimal duration of moxi floxacin treatment for $M$. hominis meningitis has not been established, but it may range from 2 to 6 weeks ${ }^{7,9)}$.

Although M. hominis is less susceptible to ciprofloxacin than to moxifloxacin, we used ciprofloxacin to treat our patient because we did not measure the sensitivity of $M$. hominis to moxifloxacin. We found ciprofloxacin to be effective against $M$. hominis meningitis.

In newborns with infectious disease, ciprofloxacin has been administered as a remedy against neonatal sepsis due to multidrug-resistant strains or sepsis with clinical signs of exacerbation under empirical antibiotic treatment. Ciprofloxacin has been reported to be effective against bacterial infections in newborns. In particular, CSF concentrations of ciprofloxacin have been found to be comparable to serum ciprofloxacin concentrations, although available data from infected neonates are limited. Moreover, ciprofloxacin has been reported to be safe and well tolerated. Although the evaluation was primarily clinical and follow-up was limited to a few months after the end of treatment, no serious side effects, especially joint toxicity, were observed ${ }^{10)}$. However, additional high-quality studies should be conducted to provide reliable data on the pharmacokinetics, efficacy, and long-term safety of ciprofloxacin in newborns.

Although a case of recovery of a full-term newborn from $M$. hominis meningitis without a specific treatment has been re ported $^{11)}$, it can cause severe neurological complications in newborns and can be fatal if diagnosis and treatment are delayed 
${ }^{3,8,9)}$. Therefore, clinical awareness of $M$. hominis meningitis is necessary when treating patients, especially newborns, with this disease.

\section{ARTICLE INFORMATION}

\section{Ethical statement}

This study was approved by the Eulji University Hospital's Institutional Review Board (approval number: 2019-04-028). Written informed consent was obtained from the parents.

\section{Conflicts of interest}

No potential conflict of interest relevant to this article was reported.

\section{Author contributions}

Conception or design: I.G., W.S.S., Y.H.S., S.Y.K.

Acquisition, analysis, or interpretation of data: I.G., W.S.S., Y.H.S., S.Y.K.

Drafting the work or revising: S.Y.K.

Final approval of the manuscript: I.G., W.S.S., Y.H.S., S.Y.K.

\section{ORICID}

Iktae Gwon https://orcid.org/0000-0001-6524-4995

Seung Yeon Kim https://orcid.org/0000-0002-7004-4821

\section{Acknowledgments}

None

\section{REFERENCES}

1. Wealthall SR. Mycoplasma meningitis in infants with spina bifida. Dev Med Child Neurol Suppl 1975;35:117-22.

2. Capoccia R, Greub G, Baud D. Ureaplasma urealyticum, Myco plasma hominis and adverse pregnancy outcomes. Curr Opin Infect Dis 2013;26:231-40.

3. Alonso-Vega C, Wauters N, Vermeylen D, Muller MF, Serruys E. A fatal case of Mycoplasma hominis meningoencephalitis in a full-term newborn. J Clin Microbiol 1997;35:286-7.

4. Woo PC, Lau SK, Teng JL, Tse H, Yuen KY. Then and now: use of 16S rDNA gene sequencing for bacterial identification and discovery of novel bacteria in clinical microbiology laboratories. Clin Microbiol Infect 2008;14:908-34.

5. Mignard S, Flandrois JP. 16S rRNA sequencing in routine bac terial identification: a 30-month experiment. J Microbiol Methods 2006;67:574-81.

6. Safarkar R, Mehrabadi JF, Noormohammadi Z, Mirnejad R. Development a rapid and accurate multiplex real time PCR method for the detection Chlamydia trachomatis and Mycoplasma hominis. J Clin Lab Anal 2017;31:e22126.

7. Watt KM, Massaro MM, Smith B, Cohen-Wolkowiez M, Benjamin DK Jr, Laughon MM. Pharmacokinetics of moxifloxacin in an infant with Mycoplasma hominis meningitis. Pediatr Infect Dis J 2012;31:197-9.

8. Hata A, Honda Y, Asada K, SasakiY, Kenri T, Hata D. Mycoplasma hominis meningitis in a neonate: case report and review. J Infect 2008;57:338-43.

9. Wildenbeest JG, Said I, Jaeger B, van Hest RM, van de Beek D, Pajkrt D. Neonate with Mycoplasma hominis meningoen cephalitis given moxifloxacin. Lancet Infect Dis 2016;16:e261-6.

10. Kaguelidou F, Turner MA, Choonara I, Jacqz-Aigrain E. Ciprofloxacin use in neonates: a systematic review of the literature. Pediatr Infect Dis J 2011;30:e29-37.

11. Huang YF, Mu XP. Mycoplasma hominis meningitis in a fullterm neonate: rapid recovery without specific treatment. Indian J Pediatr 2016;83:1030-1. 